\title{
Development of a screening tool for pregnant women who need social support at obstetric institutions: A prospective cohort study
}

\section{Haruna Kawaguchi ( $\sim$ haruna@wch.opho.jp)}

Osaka Women's and Children's Hospital

\section{Ryoji Shinohara}

University of Yamanashi

\section{Yuka Akiyama \\ University of Yamanashi \\ Megumi Kushima \\ University of Yamanashi \\ Yoshio Matsuda \\ Toho Medical Clinic \\ Marie Yoneyama \\ Tokyo Healthcare University \\ Tomomi Yamamoto \\ International Catholic Hospital \\ Zentaro Yamagata \\ University of Yamanashi}

\section{Research Article}

Keywords: pregnant women in need of social support, obstetric institutions, interview sheet during pregnancy, screening tool, maternal mental health,child maltreatment

Posted Date: February 17th, 2022

DOI: https://doi.org/10.21203/rs.3.rs-1361647/v1

License: (c) (i) This work is licensed under a Creative Commons Attribution 4.0 International License. Read Full License 


\section{Abstract \\ Background}

To develop an efficient interview sheet and the screening tool to detect pregnant women in need of social support at obstetric institutions.

\section{Methods}

A prospective cohort study was conducted at three medical institutions that were familiar with social issues. The pregnant women were assessed using an interview sheet at the first visit $(n=678)$, at approximately 28 weeks gestation ( $n=495), 36$ weeks gestation $(n=296)$, and the postpartum period $(n=822)$. We investigated the considered important items on the interview sheet for women in need of social support who were selected based on conferences at three medical institutions. The primary outcome was to develop the available interview sheet during pregnancy and the screening tool to detect pregnant women in need of support to require collaboration with a public health center. The items on the interview sheet were scored by multiple linear regression analysis, and the cutoff values were calculated using the receiver operating characteristic curve. The secondary outcome was to investigate the perinatal factors associated with the Edinburgh postnatal depression scale (EPDS). The association between perinatal factors and EPDS was assessed using multiple logistic regression analyses.

\section{Results}

One hundred sixty-six cases for which all interview sheets for all periods were available. Interview sheets and stepwise screening tools during the first and second trimester were developed in which $2.5 \%$ of pregnant women were identified as requiring social support, respectively. The factors associated with EPDS $\geqq 9$ were 'Women who felt confused/troubled or did not feel anything to be pregnant' (adjusted odds ratio [aOR]: 6.51, 95\% confidence interval [CI]: 1.62-26.15), 'Maternal mental disorder' (aOR 4.38; Cl 1.06-18.10), 'Consultation request at first visit' (aOR 3.22; $\mathrm{Cl} 1.09-9.45$ ), and 'Women who have difficulty or anxiety about pregnancy during the second trimester' (aOR 3.14; Cl 1.29-7.67).

\section{Conclusions}

We created the interview sheets and screening tools for three steps during the first and the second trimester. Future studies are needed to validate these screening tools.

\section{Background}

Among the verified child abuse cases which resulted in death [1], children under 1 year of age accounted for about $50 \%$ among the deaths due to childhood maltreatment, and half of them are within the first month of life. It suggests the importance of early preventive efforts against child maltreatment during pregnancy. It is reported that the background factors related to child maltreatment were unexpected/unplanned pregnancies, failure to receive pregnancy health checkups, failure to receive the Maternal and Child Health Handbook, and teenage pregnancies $[1,2]$. Other factors such as unmarried mothers, maternal mental disorder, low educational achievement, a history 
of childhood abuse, deprivation, and low-birth-weight children have also been reported to be associated with child maltreatment [2-4]. It is important to understand such social risk factors as well as medical risk factors.

Identifying social risk factors at the time of pregnancy and initiating support for pregnant women who need social support may help reduce child maltreatment.

Although there are many public health centers that detect pregnant women who need social support through questionnaires and interviews when issuing the Maternal and Child Health Handbook, it is limited due to the few opportunities for contact with pregnant women. On the other hand, pregnancy health checkups at obstetric institutions are scheduled at least 14 times in Japan. In pregnancy health checkups, the mother's health condition is assessed, and a medical examination and health guidance are conducted. Health guidance has the role of taking care of the mental health of pregnant women and relieving their anxiety about pregnancy, childbirth, and childcare. However, about half of the delivery facilities in Japan are private obstetric clinics, and some facilities are inadequate for resolving social and psychological problems. Therefore, the aim of this study is to develop a screening tool for detecting pregnant women in need of support that can be used in health guidance at all facilities, including private obstetric clinics.

\section{Methods}

This was a prospective cohort study conducted at three medical institutions that were familiar with social issues.

We created new interview sheets at the first visit, at approximately 28 weeks gestation, 36 weeks gestation, and the postpartum period. Table 1 shows the items of interview sheets for each period. These interview sheets were conducted at three medical institutions (Osaka Women's and Children's Hospital, Seibo Hospital, and Showa University Hospital) that use their own methods to identify pregnant women in need of support and collaborate with a public health center. In addition, the Edinburgh postnatal depression scale (EPDS) was administered together at one-month postpartum. At the three medical institutions, information was collected from face-to-face interviews, impressions based on behavior and actions, medical information, and original questionnaires. Pregnant women in need of administrative cooperation were selected by conferences at Osaka Women's and Children's Hospital and Seibo Hospital and by nurses specializing in maternity nursing at Showa University. The members of the conference at Osaka Mothers and Children were nurses, midwives, public health nurses, caseworkers, and obstetricians, while the members at Seibo Hospital were nurses, midwives, caseworkers, and pediatricians. 
Table 1

Interview sheets for each period

\begin{tabular}{|c|c|c|}
\hline At first visit & Positive & Negative \\
\hline $\begin{array}{l}\text { Maternal feelings toward being } \\
\text { pregnant }\end{array}$ & Happy & $\begin{array}{l}\text { Confused, Trouble, Did not feel anything } \\
\text { to be pregnant }\end{array}$ \\
\hline $\begin{array}{l}\text { Partner's feelings toward being } \\
\text { pregnant }\end{array}$ & Happy & $\begin{array}{l}\text { Confused, Trouble, Did not feel anything } \\
\text { to be pregnant }\end{array}$ \\
\hline Depression symptoms & Nothing/ Very few & Sometimes/Often \\
\hline Family and social support & Yes & No \\
\hline Economic status & No problem & Deprived / Need of public assistance \\
\hline Partner's status & Married & Unmarried/ Remarried \\
\hline Maternal mental disorder & No & Yes \\
\hline Use of mother's illegal drug & No & Yes \\
\hline Use of partnerr's illegal drug & No & Yes \\
\hline Worries about older child & No & Yes \\
\hline Consultation request & No & Yes \\
\hline Number of fetuses & Singleton pregnancies & Multiple pregnancies \\
\hline $\begin{array}{l}\text { Number of children } \\
\text { (exclusive of this pregnancy) }\end{array}$ & $<3$ & $\geqq 3$ \\
\hline Maternal age & $<25$ & $\geqq 25$ \\
\hline Second trimester & Positive & Negative \\
\hline Maternity life & Almost happy & Difficulty / Anxiety \\
\hline Talking with partner & Very often /Sometimes & Very few /Nothing \\
\hline Partner violence & No & Yes \\
\hline Worries about older child & No & Yes \\
\hline Parent's own childhood abuse & No & Yes \\
\hline Depression symptoms & Nothing/ Very few & Sometimes/Often \\
\hline Family and social support & Yes & No \\
\hline Smoking & $\begin{array}{l}\text { No/ Discontinued after } \\
\text { pregnant }\end{array}$ & Continued after pregnant \\
\hline Alcohol use & $\begin{array}{l}\text { No/ Discontinued after } \\
\text { pregnant }\end{array}$ & Continued after pregnant \\
\hline Consultation request & No & Yes \\
\hline
\end{tabular}

EPDS; the Edinburgh postnatal depression scale 


\begin{tabular}{|lll|}
\hline At first visit & Positive & Negative \\
\hline Status of pregnancy health checkups & Usual & Less/ Unscheduled \\
\hline Third trimester & Positive & Negative \\
\hline Depression symptoms & Nothing/ Very few & Sometimes/Often \\
\hline Worries about older child & No & Yes \\
\hline $\begin{array}{l}\text { Concerns about the course of } \\
\text { pregnancy }\end{array}$ & No & Yes \\
\hline Family and social support & Yes & No \\
\hline Childbirth preparation & Almost finished & Unfinished \\
\hline Consultation request & No & Yes \\
\hline Pregnancy health checkups & Usual & Less/ Unscheduled \\
\hline $\begin{array}{l}\text { Fetal congenital disease or fetal } \\
\text { growth restriction }\end{array}$ & No & Yes \\
\hline Postpartum & Positive & Negative \\
\hline Fental condition after childbirth & No & Yes \\
\hline Feelings toward childcare & Happy & Neither/Unhappy \\
\hline Partner's support & Often/Sometimes & Few \\
\hline Family and social support & Yes & No \\
\hline Difficulty of childcare & Nothing /Sometimes & Often \\
\hline Consultation request & No & Yes \\
\hline EPDS & $<9$ & $\geqq 9$ \\
\hline EPDS; the Edinburgh postnatal depression scale & \\
\hline
\end{tabular}

We investigated the considered important items on the new interview sheet for women in need of social support who were selected based on conferences at three medical institutions. The primary outcome was to develop an available interview sheet during pregnancy and the screening tool to detect pregnant women in need of support in collaboration with a public health center. A secondary outcome was to investigate the perinatal factors associated with EPDS.

Standardized partial regression coefficients were calculated by multiple linear regression analysis to refine and score each item on the interview sheet. Scores were calculated by multiplying the standardized partial regression coefficient by 100 and rounding it off to the closest whole. The cutoff value was calculated by the receiver operating characteristic (ROC) curve. The variance inflation factor was calculated using regression analysis to confirm multi-collinearity in the multivariate analysis. The association between perinatal factors and EPDS was assessed using multiple logistic regression analysis. All statistical analyses were performed using SPSS Statistics ver. 27 software. Two-sided P-values of $<0.05$ were considered statistically significant. 
This research related to human use is in compliance with all the relevant national regulations, institutional policies and the tenets of the Helsinki Declaration. This research was approved by the Ethics Review Board of the University of Yamanashi (approval number 1663, approval date July 10, 2017). Written informed consent was obtained from all study subjects. At the time the interview sheets from the three medical institutions were mailed to the University of Yamanashi, the data center, research IDs were assigned, and names and IDs for each hospital were deleted. The matching forms of research IDs and hospital-specific IDs were managed at each institution.

\section{Results}

Table 2 showed the number of responses to the interview sheet and the number of pregnant women in need of social support who were judged to need cooperation with the public health center at each of the periods. We received 678 responses at the first visit, 495 during the second trimester, 296 during the third trimester, and 822 for postpartum. Figure 1 showed that the change in support status during pregnancy and postpartum for the 166 cases for which all interview sheets for all periods were available. In this study, we investigated socially high-risk pregnant women who were supported by their respective obstetric institutions as well as collaborating with a public health center. In the first trimester, the number of pregnant women in need of support to require collaboration with a public health center was $2 \%$, and the number of socially high-risk pregnant women was $17 \%$. During the second and third trimesters, the number of pregnant women in need of support to require collaboration with public health centers was $6 \%$, which was higher than that in early pregnancy, and it was the highest at $23 \%$ in the postpartum period. There was a change in the support status during pregnancy. There were some cases in which cooperation with public health centers was started but later changed to support at the respective medical institutions or some cases in which support was no longer needed. There were also 13 cases where there were no problems during pregnancy, but support was needed after delivery. 
Table 2

the number of pregnant women in need of social support who were judged to need cooperation with the public health center at each of the periods

\begin{tabular}{|c|c|c|c|c|}
\hline & Osaka§ & Seibo' & Showa & Total \\
\hline \multicolumn{5}{|l|}{ First visit } \\
\hline Number of cases & 279 & 120 & 277 & 678 \\
\hline Missing data & 7 & 0 & 2 & 9 \\
\hline Social high-risk pregnant women ${ }^{\dagger}$ & $41(15 \%)$ & 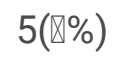 & $67(24 \%)$ & $113(17 \%)$ \\
\hline Women in need of social support ${ }^{\ddagger}$ & $8(3 \%)$ & 0 & $6(2 \%)$ & $14(2 \%)$ \\
\hline \multicolumn{5}{|l|}{ Second trimester } \\
\hline Number of cases & 225 & 46 & 224 & 495 \\
\hline Missing data & 10 & 1 & 0 & 11 \\
\hline Social high-risk pregnant women $^{\dagger}$ & $23(11 \%)$ & $3(7 \%)$ & $8(4 \%)$ & $34(7 \%)$ \\
\hline Women in need of social support ${ }^{\ddagger}$ & $9(4 \%)$ & 0 & $21(9 \%)$ & $30(6 \%)$ \\
\hline \multicolumn{5}{|l|}{ Third trimester } \\
\hline Number of cases & 171 & 40 & 85 & 296 \\
\hline Missing data & 13 & 0 & 1 & 14 \\
\hline Social high-risk pregnant women ${ }^{\dagger}$ & $17(11 \%)$ & $2(5 \%)$ & $18(12 \%)$ & $37(13 \%)$ \\
\hline Women in need of social support ${ }^{\ddagger}$ & $8(5 \%)$ & 0 & $10(12 \%)$ & $18(6 \%)$ \\
\hline \multicolumn{5}{|l|}{ Postpartum } \\
\hline Number of cases & 199 & 61 & 562 & 822 \\
\hline Missing data & 8 & 1 & 294 & 303 \\
\hline Social high-risk pregnant women ${ }^{\dagger}$ & $5(3 \%)$ & $4(7 \%)$ & $99(38 \%)$ & $108(21 \%)$ \\
\hline
\end{tabular}

Data are shown as n(\%).

† social high-risk pregnant women: pregnant women with social problems supported by their respective obstetric institutions

‡ women in need of social support: pregnant women in need of social support who were judged to need cooperation with the public health center at each of the periods

Osaka: Osaka Women's and Children's Hospital

Seibo: Seibo Hospital

Showa: Showa University Hospital 


\begin{tabular}{|c|c|c|c|c|}
\hline & Osaka§ & Seibo' & Showa & Total \\
\hline Women in need of social support ${ }^{\ddagger}$ & $37(19 \%)$ & $2(3 \%)$ & $80(30 \%)$ & $119(23 \%)$ \\
\hline \multicolumn{5}{|l|}{ Data are shown as $\mathrm{n}(\%)$} \\
\hline \multicolumn{5}{|c|}{$\begin{array}{l}\text { † social high-risk pregnant women: pregnant women with social problems supported by their respective } \\
\text { obstetric institutions }\end{array}$} \\
\hline \multicolumn{5}{|c|}{$\begin{array}{l}\text { ¥ women in need of social support: pregnant women in need of social support who were judged to need } \\
\text { cooperation with the public health center at each of the periods }\end{array}$} \\
\hline \multicolumn{5}{|c|}{ Osaka: Osaka Women's and Children's Hospital } \\
\hline \multicolumn{5}{|l|}{ Seibo: Seibo Hospital } \\
\hline Showa: Showa University Hospital & & & & \\
\hline
\end{tabular}

Table 3 shows the results of the multiple linear regression analysis at the first visit. Compared to the results of the single regression analysis (Model-1) for each item, in the multiple regression analysis in which all factors were input, the results of the items " partner's feelings toward being pregnant " and " consultation request " were reversed, so they were excluded from the study. Furthermore, among the items on the interview sheet, "the use of mother's and partner's illegal drug" were excluded from the screening tool because they clearly required cooperation with a public health center. The questionnaire after exclusion of the four items was used as Model-2, and the score of each item was calculated. The cutoff value for the detection of pregnant women in need of social support was calculated to be 22 points from the ROC curve, and scores of 22 points or more were selected as STEP-1, with an area under the curve (AUC) of 0.96 , the sensitivity of 0.92 , and specificity of 0.92 . Of the 558 subjects analyzed at the first visit, 54 cases were detected for STEP-1. In order to further improve the selection rate, we checked the applicable percentage of each item in the group that actually had cooperation with a public health center in this study. The factors that accounted for more than $30 \%$ of the total were "no family and social support," "maternal mental disorder," "worry about the older child," and "multiple pregnancies," and those who had at least one of these four factors were selected as STEP-2 in addition to STEP-1. As a result, 20 cases were selected, of which six cases $(30 \%)$ were actually involved in cooperation with a public health center. In addition, those with at least two of the following were selected as STEP-3: "depression symptoms," "maternal mental disorder," and " consultation request." The number of pregnant women in need of social support based on the screening by three STEPs was 14 , of which $5(36 \%)$ actually required administrative cooperation. The number of positive screening results was 14 (2.5\%) out of 558. The screening tool is shown in Fig. 2. 
Table 3

The multiple linear regression analysis at first visit

\begin{tabular}{|c|c|c|c|c|c|c|c|c|c|}
\hline \multirow[b]{2}{*}{ Items } & \multicolumn{3}{|c|}{ Model-1(clude) } & \multicolumn{6}{|c|}{ Model-2(adjusted) $(n=554)$} \\
\hline & OR & $95 \% \mathrm{Cl}$ & $P$ & SPRC & Score & OR & $95 \% \mathrm{Cl}$ & $P$ & VIF \\
\hline \multicolumn{10}{|c|}{ Maternal feelings toward being pregnant } \\
\hline Happy & 1 & Reference & & & & 1 & Reference & & \\
\hline $\begin{array}{l}\text { Unhappy } \\
\text { etct }\end{array}$ & 10.985 & $\begin{array}{l}3.966- \\
30.422\end{array}$ & 0 & 0.069 & 6.9 & 2.72 & $\begin{array}{l}0.509- \\
14.527\end{array}$ & 0.242 & 1.095 \\
\hline \multicolumn{5}{|c|}{ Partner's feelings toward being pregnant } & प & & & & \\
\hline Happy & 1 & Reference & & & & & & & \\
\hline $\begin{array}{l}\text { Unhappy } \\
\text { etct }\end{array}$ & 5.566 & $\begin{array}{l}1.723- \\
17.98\end{array}$ & 0.004 & & & & & & \\
\hline \multicolumn{10}{|c|}{ Depression symptoms } \\
\hline No & 1 & Reference & & & & 1 & Reference & & \\
\hline Yes & 3.987 & $\begin{array}{l}1.135- \\
14.005\end{array}$ & 0.031 & 0.019 & 1.9 & 1.794 & $\begin{array}{l}0.312- \\
10.298\end{array}$ & 0.512 & 1.058 \\
\hline \multicolumn{10}{|c|}{ Family and social support } \\
\hline Yes & 1 & Reference & & & & 1 & Reference & & \\
\hline No & 13.489 & $\begin{array}{l}1.325- \\
137.317\end{array}$ & 0.028 & 0.117 & 11.7 & 32.455 & $\begin{array}{l}1.386- \\
759.856\end{array}$ & 0.031 & 1.059 \\
\hline \multicolumn{10}{|c|}{ Economic status } \\
\hline No problem & 1 & Reference & & & & 1 & Reference & & \\
\hline Poverty & 10.235 & $\begin{array}{l}3.787- \\
27.66\end{array}$ & 0 & 0.076 & 7.6 & 2.24 & $\begin{array}{l}0.473- \\
10.613\end{array}$ & 0.31 & 1.167 \\
\hline \multicolumn{10}{|c|}{ Partner's status } \\
\hline Married & 1 & Reference & & & & 1 & Reference & & \\
\hline $\begin{array}{l}\text { Unmarried/ } \\
\text { remarried }\end{array}$ & 6.433 & $\begin{array}{l}2.324- \\
17.812\end{array}$ & 0 & 0.129 & 12.9 & 6.068 & $\begin{array}{l}1.33- \\
27.686\end{array}$ & 0.02 & 1.086 \\
\hline \multicolumn{10}{|c|}{ Maternal mental disorder } \\
\hline No & 1 & Reference & & & & 1 & Reference & & \\
\hline
\end{tabular}

OR: odds ratio

95\%Cl: 95\% confidential interval

VIF: variance inflation factor

SPRC: standardized partial regression coefficient

t:confused, trouble, did not feel anything to be pregnant 


\begin{tabular}{|c|c|c|c|c|c|c|c|c|c|}
\hline \multirow{2}{*}{ Yes } & \multicolumn{3}{|c|}{ Model-1(clude) } & \multicolumn{6}{|c|}{ Model-2(adjusted)( $n=554)$} \\
\hline & 13.593 & $\begin{array}{l}4.653- \\
39.709\end{array}$ & 0 & 0.16 & 16 & 11.131 & $\begin{array}{l}1.662- \\
74.542\end{array}$ & 0.013 & 1.034 \\
\hline \multicolumn{5}{|c|}{ Use of mother's illegal drug } & \multicolumn{5}{|l|}{ प } \\
\hline No & 1 & Reference & & & & & & & \\
\hline Yes & 0 & 0 & 0.999 & & & & & & \\
\hline \multicolumn{5}{|c|}{ Use of partnerr's illegal drug } & \multicolumn{5}{|l|}{ प } \\
\hline No & 1 & Reference & & & & & & & \\
\hline Yes & 0 & 0 & 0.999 & & & & & & \\
\hline \multicolumn{10}{|c|}{ Worries about older child } \\
\hline No & 1 & Reference & & & & 1 & Reference & & \\
\hline Yes & 2.154 & $\begin{array}{l}0.685- \\
6.767\end{array}$ & 0.189 & 0.028 & 2.8 & 2.917 & 0.367 & 0.312 & 1.02 \\
\hline \multicolumn{5}{|c|}{ Consultation request } & \multicolumn{5}{|l|}{ 口 } \\
\hline No & 1 & Reference & & & & & & & \\
\hline Yes & 3.689 & $\begin{array}{l}1.322- \\
10.296\end{array}$ & 0.013 & & & & & & \\
\hline \multicolumn{10}{|c|}{ Number of fetuses } \\
\hline Singleton & 1 & Reference & & & & 1 & Reference & & \\
\hline Multiple & 4.96 & 1.049 & 0.043 & 0.105 & 10.5 & 14.601 & 1.557 & 0.019 & 1.01 \\
\hline \multicolumn{10}{|c|}{ Number of children } \\
\hline$<3$ & 1 & Reference & & & & 1 & Reference & & \\
\hline$\geqq \square$ & 7.239 & 1.903 & 0.004 & 0.141 & 14.1 & 19.624 & 2.45 & 0.005 & 1.103 \\
\hline \multicolumn{10}{|c|}{ Maternal age } \\
\hline$\geqq 25$ & 1 & Reference & & & & 1 & Reference & & \\
\hline$<25$ & 15.49 & 4.909 & 0 & 0.212 & 21.2 & 37.134 & 5.458 & 0 & 1.039 \\
\hline \multicolumn{10}{|c|}{ OR: odds ratio } \\
\hline \multicolumn{10}{|c|}{ 95\%Cl: $95 \%$ confidential interval } \\
\hline \multicolumn{10}{|c|}{ VIF: variance inflation factor } \\
\hline \multicolumn{10}{|c|}{ SPRC: standardized partial regression coefficient } \\
\hline †:confused & uble, did & feel anyth & o be p & ynant & & & & & \\
\hline
\end{tabular}

Table 4 shows the results of the multiple linear regression analysis during the second trimester. Compared to the results of the single regression analysis (Model-1) for each item, in the multiple regression analysis in which all 
factors were entered, the item " worries about the older child " was reversed, so it was excluded from the study. In addition, "alcohol use" and " status of pregnancy health checkups "were excluded because they could not be analyzed due to missing data. The interview sheets after the exclusion of the three items were used as Model-2, and the scores for each item were calculated. The cutoff value for pregnant women in need of social support was determined to be 14 points from the ROC curve, and scores of 14 points or more were extracted as STEP- 1 , with an AUC of 0.77 , sensitivity of 0.82 , and specificity of 0.62 . Of the 483 cases analyzed during the second trimester, 110 cases were extracted by STEP-1, of which 34 cases (31\%) were had cooperation with public health centers in this study. In order to increase the selection rate, we examined the factors on the interview sheets of the women who scored more than 14 points. However, since the percentage of the risk group was more than $30 \%$ for all items, we calculated the Spearman correlation coefficient for the subjects with 14 points or more, weighted the correlation coefficient by a factor of 10 , and considered variables with 2 points or more to be factors with higher risk. These items were " no talking with partner," "partner violence," and "smoking," and if any of these items were applicable, they were narrowed down as STEP-2 in addition to STEP-1. Twenty-one people were selected for STEP-1 and STEP2 , of which 12 (57\%) required administrative cooperation in this study. In addition, STEP-3 was selected for those who had at least one of the following: "no talking with partner," "partner violence," "depression symptoms," and "consultation request. As a result, 12 cases were selected, and all of them were the subjects of the actual administrative collaboration in this study. 
Table 4

The multiple linear regression analysis during the second trimester

\begin{tabular}{|c|c|c|c|c|c|c|c|c|c|}
\hline & Model-1 & & & Model & (adjust & d) $(n=4$ & & & \\
\hline Items & $\mathrm{OR}$ & $95 \% \mathrm{Cl}$ & $P$ & SPRC & score & OR & $95 \% \mathrm{Cl}$ & $P$ & VIF \\
\hline \multicolumn{10}{|c|}{ Maternity life } \\
\hline Happy & 1 & reference & & & & 1 & reference & & \\
\hline $\begin{array}{l}\text { Difficulty } \\
\text { /Anxiety }\end{array}$ & 4.165 & $\begin{array}{l}2.306- \\
7.525\end{array}$ & 0 & 0.167 & 17 & 3.19 & $\begin{array}{l}1.603- \\
6.35\end{array}$ & 0.001 & 1.119 \\
\hline \multicolumn{10}{|c|}{ Talking with partner } \\
\hline Yes & 1 & reference & & & & 1 & reference & & \\
\hline No & 6.773 & $\begin{array}{l}2.413- \\
19.008\end{array}$ & 0 & 0.108 & 11 & 3.102 & $\begin{array}{l}0.819- \\
11.752\end{array}$ & 0.096 & 1.233 \\
\hline \multicolumn{10}{|c|}{ Partner violence } \\
\hline No & 1 & reference & & & & 1 & reference & & \\
\hline Yes & 12.918 & $\begin{array}{l}3.523- \\
47.367\end{array}$ & 0 & 0.15 & 15 & 7.081 & $\begin{array}{l}1.502- \\
33.388\end{array}$ & 0.013 & 1.236 \\
\hline \multicolumn{10}{|c|}{ Worries about older child } \\
\hline No & 1 & reference & & & & & & & \\
\hline Yes & 1.342 & $\begin{array}{l}0.598- \\
3.009\end{array}$ & 0.476 & & & & & & \\
\hline
\end{tabular}

Parent's own childhood abuse

\begin{tabular}{llllllllll} 
No & 1 & reference & \multicolumn{5}{c}{1} & reference \\
Yes & 6.413 & $2.695-$ & 0 & 0.135 & 14 & 3.566 & $1.281-$ & 0.015 & 1.083
\end{tabular}

Depression symptoms

\begin{tabular}{|c|c|c|c|c|c|c|c|c|c|}
\hline No & 1 & reference & & & & 1 & reference & & \\
\hline Yes & 2.74 & $\begin{array}{l}1.547- \\
4.852\end{array}$ & 0.001 & 0.058 & 6 & 1.531 & $\begin{array}{l}0.785- \\
2.984\end{array}$ & 0.211 & 1.114 \\
\hline
\end{tabular}

Family and social support

\begin{tabular}{|c|c|c|c|c|c|c|c|c|c|}
\hline Yes & 1 & reference & & & & 1 & reference & & \\
\hline No & 7.691 & $\begin{array}{l}0.474- \\
124.717\end{array}$ & 0.151 & 0.072 & 7 & 7.517 & $\begin{array}{l}0.407- \\
138.934\end{array}$ & 0.175 & 1.004 \\
\hline
\end{tabular}

OR: odds ratio

95\%Cl: 95\% Confidential Interval

VIF: Variance Inflation Factor

SPRC:standardized partial regression coefficient 


\begin{tabular}{|c|c|c|c|c|c|c|c|c|c|}
\hline & \multicolumn{3}{|l|}{ Model-1(clude) } & \multicolumn{6}{|c|}{ Model-2(adjusted)(n = 472) } \\
\hline \multicolumn{10}{|l|}{ Smoking } \\
\hline No & 1 & reference & & & & 1 & reference & & \\
\hline Yes & 24.113 & $\begin{array}{l}2.464- \\
236.008\end{array}$ & 0.006 & 0.165 & 17 & 26.667 & $\begin{array}{l}2.316- \\
306.98\end{array}$ & 0.008 & 1.019 \\
\hline \multicolumn{10}{|l|}{ Alcohol use } \\
\hline No & 1 & reference & & & & & & & \\
\hline Yes & 0 & 0 & 0.999 & & & & & & \\
\hline \multicolumn{10}{|c|}{ Consultation request } \\
\hline No & 1 & reference & & & & 1 & reference & & \\
\hline Yes & 2.051 & $\begin{array}{l}1.158- \\
3.632\end{array}$ & 0.014 & 0.053 & 5 & 1.499 & $\begin{array}{l}0.78- \\
2.881\end{array}$ & 0.225 & 1.064 \\
\hline \multicolumn{10}{|c|}{ Pregnancy health checkups } \\
\hline usual & 1 & reference & & & & & & & \\
\hline $\begin{array}{l}\text { less/ } \\
\text { unscheduled }\end{array}$ & 12541959234 & 0 & 1 & & & & & & \\
\hline \multicolumn{10}{|c|}{ OR: odds ratio } \\
\hline \multicolumn{10}{|c|}{ 95\%Cl: 95\% Confidential Interval } \\
\hline \multicolumn{10}{|c|}{ VIF: Variance Inflation Factor } \\
\hline SPRC:standar & ed partial reg & on coe & & & & & & & \\
\hline
\end{tabular}

The number of positive cases by the screening by three STEPs was 12 out of $483(2.5 \%)$. The screening tool is shown in Fig. 3.

Table 5 shows the results of the multiple linear regression analysis during the third trimester. Each item on the interview sheets was scored, and a cutoff value of 7 points was calculated using the ROC curve. The AUC, sensitivity, and specificity were $0.46,0.43$, and 0.57 , respectively, which were inappropriate for screening. 
Table 5

The multiple linear regression analysis during the third trimester

\begin{tabular}{|lclllllll|}
\hline \multicolumn{7}{|c}{ Model-1(clude) } & \multicolumn{7}{c|}{ Model-2(adjusted)( $\mathbf{n = 2 9 6 )}$} \\
\hline Items & OR & $95 \% \mathrm{Cl}$ & $P$ & SPRC & score & OR & $95 \% \mathrm{Cl}$ & $P$ \\
\hline Depression symptoms & & & & & & & \\
\hline No & 1 & reference & & & & 1 & reference & \\
\hline Yes & 2.329 & $0.617-$ & 0.2123 & 0.288 & 29 & 2.865 & $0.54-$ & 0.2165 \\
& 8.793 & & & & & 15.204 & \\
Worries about older child & & & & & & & \\
No & 1 & reference & & & & 1 & reference & \\
Yes & 3.039 & $0.872-$ & 0.0809 & 0.1226 & 12 & 1.88 & $0.344-$ & 0.4664 \\
& & 10.591 & & & & & 10.28 & \\
\hline
\end{tabular}

Concerns about the course of pregnancy

$\begin{array}{llll}\text { No } & 1 & \text { reference } & \\ \text { Yes } & 2.483 & 0.73- & 0.1453 \\ & & 8.446 & \end{array}$

Family and social support

\begin{tabular}{lllllllll} 
Yes & 1 & reference & & & 28 & 1 & \multicolumn{2}{c}{ reference } \\
No & 53.397 & $4.462-$ & 0.0017 & 0.276 & & 124.973 & $3.724-$ & 0.0071 \\
& & 638.95 & & & & & $>999.9$ &
\end{tabular}

Childbirth preparation

\begin{tabular}{lllllllll} 
finished & 1 & reference & & & \multicolumn{3}{c}{1} & \multicolumn{2}{c}{ reference } \\
unfinished & 3.416 & $\begin{array}{l}0.386- \\
30.227\end{array}$ & 0.2695 & 0.0653 & 7 & 2.027 & $0.144-$ & 0.6006 \\
& & & & & & 28.527 &
\end{tabular}

Consultation request

\begin{tabular}{llllllllll} 
No & 1 & reference & & & \multicolumn{3}{c}{1} & \multicolumn{2}{c}{ reference } \\
Yes & 4.458 & $1.306-$ & 0.017 & 0.5232 & 52 & 7.603 & $1.54-$ & 0.0128 \\
& & 15.218 & & & & & 37.545 &
\end{tabular}

Pregnancy health checkups

\begin{tabular}{|c|c|c|c|c|c|c|c|c|}
\hline usual & 1 & reference & & & & 1 & reference & \\
\hline $\begin{array}{l}\text { less/ } \\
\text { unscheduled }\end{array}$ & 12.182 & $\begin{array}{l}1.025- \\
144.745\end{array}$ & 0.0477 & 0.2416 & 24 & 68.484 & $\begin{array}{l}3.034- \\
>999.9\end{array}$ & 0.0079 \\
\hline
\end{tabular}

Fetal congenital disease or fetal growth restriction

OR: odds ratio

95\% Cl: 95\% Confidential Interval

VIF: Variance Inflation Factor SPRC:standardized partial regression coefficient 


\begin{tabular}{|c|c|c|c|c|c|c|c|c|}
\hline \multirow[b]{2}{*}{ No } & \multicolumn{3}{|c|}{ Model-1(clude) } & \multicolumn{5}{|c|}{ Model-2(adjusted) $(n=296)$} \\
\hline & 1 & referenc & & & & 1 & referenc & \\
\hline Yes & 7 & $\begin{array}{l}1.923- \\
25.48\end{array}$ & 0.0032 & 0.4354 & 44 & 18.455 & $\begin{array}{l}3.628- \\
93.887\end{array}$ & 0.0004 \\
\hline \multicolumn{9}{|c|}{ OR: odds ratio } \\
\hline \multicolumn{9}{|c|}{ 95\%Cl: 95\% Confidential Interval } \\
\hline \multicolumn{9}{|c|}{ VIF: Variance Inflation Factor SPRC:standardized partial regression coefficient } \\
\hline
\end{tabular}

In addition, we examined the relationship between the EPDS at the one-month postpartum and each item on the interview sheets. The factor "no family and social support" and "mother or partner's use of illegal drugs" at the first visit, and "no family and social support," "alcohol use," and "less or excess pregnancy health checkups" during the second trimester were excluded due to their small number. The factors associated with EPDS $\geqq 9$ were 'Women who felt confused/troubled or did not feel anything to be pregnant' (adjusted odds ratio [aOR]: $6.51,95 \%$ confidence interval [Cl]: 1.62-26.15), 'Maternal mental disorder'(aOR 4.38, Cl $106-18.10)$, 'Consultation request at first visit' (aOR 3.22, $\mathrm{Cl} 1.09-9.45$ ), and 'Women who have difficulty or anxiety about pregnancy during the second trimester' (aOR 3.14, $\mathrm{Cl} 1.29-7.67)$. The factor "less or excess pregnancy health checkups" during the third trimester was excluded due to the small number of cases, and no factor associated with EPDS was found.

\section{Discussion}

The interview sheets and the stepwise screening tool by three STEPs tools during the first and second trimester were developed in which $2.5 \%$ of pregnant women were identified as requiring social support, respectively. The screening tool was created with the goal of being able to detect women, even in obstetric clinics that were not familiar with social issues, automatically. The screening tool was created with the intention of narrowing down the number of targets because if there are too many targets, the health center may not be able to handle them. According to a survey in Osaka Prefecture, cases of deliveries of little or no receiving for pregnancy health checkups accounted for about $0.3 \%$. (Unpublished data) In addition, the frequency of specified expectant mothers was reported to be $2-5 \%[5,6]$. Specified expectant mothers are defined in the Child Welfare Act as "pregnant women who are recognized as being in particular need of support during pregnancy with regard to postpartum care." A specified expectant mother is determined by the health center. In this study, we aim to identify pregnant women in need of social support or those who are expected to consider specified pregnant women. This study aims to detect pregnant women in need of support in collaboration with health centers, that is, cases corresponding to specified pregnant women. The detection rate using these screening tools is about $2.5 \%$ during the first and the second trimester, respectively, which is considered to be a reasonable number. In the future, it will be necessary to verify whether these interview sheets and screening tools can appropriately identify pregnant women in need of social support, and we are planning to create a system that can automatically identify pregnant women in need of social support by inputting the results of the interview sheets.

The frequency of postpartum depression is reported to be $5-10 \%$ in a prospective study in Japan [7] and $9 \%$ in the final report of the "Healthy Parents and Children 21" [8]. Furthermore, postpartum depression may lead to maternal suicide as well as child maltreatment [9-11]. In Japan, a suicide prevention program (Nagano model) [12] has been developed to improve postpartum mental health and reduce maternal suicide, and its effectiveness has been 
reported. In the present study, the factors associated with EPDS $\geqq 9$ at one-month postpartum were 'Women who felt confused/troubled or did not feel anything to be pregnant,' 'Maternal mental disorder,' 'Consultation request at first visit,' and 'Women who have difficulty or anxiety about pregnancy during the second trimester.' Although postpartum depression may develop unexpectedly, it has been suggested that it is related to maternal mental disorder, unwanted pregnancy, and anxiety during pregnancy. According to the reports of the Japan Environment and Children's Study, compared with women who felt very happy to be pregnant, those whose pregnancy was unintended but happy, unintended and confused, those who felt troubled, and those who felt no emotion toward being pregnant had increased risks of postpartum depression [13].

The strength of this study is a prospective survey conducted in several obstetric institutions that are specialized in addressing social issues, and various criteria were used to determine the detection of pregnant women in need of social support. In addition, considering the possibility of changes in the mother's and family's condition during pregnancy and background factors that may become apparent through the establishment of a relationship between the mother and the obstetric institution, interview sheets and screening tools were developed that included items tailored to each period and items common to all periods.

Several limitations should be addressed. First, less than half of the cases had a complete questionnaire for all time periods. This was due to the fact that two of the three facilities in this study handle a large number of medically high-risk pregnancies, which may result in first visits at various times. Second, although it had been reported that a late first visit is associated with pregnant women in need of social support, it was not included in this study. This was because the study includes many cases in which the first visit was made after the second trimester due to medical risks. Finally, this study was conducted up to one month after childbirth, and the relationship with the need for support at a public health center after that was unknown. Although it would be desirable to collate the data with information from the public health center if there was an actual fear of child maltreatment several months after the birth, it was difficult to obtain the data from the public health center from the viewpoint of personal information protection. In a survey such as this one, it is considered necessary to create an environment where medical institutions and government agencies can collaborate to collect information in Japan.

\section{Conclusions}

We developed the interview sheets and the stepwise screening tools during the first and the second trimester to detect pregnant women in need of support to require collaboration with a public health center. We are planning to validate these interview sheets and screening tools at obstetrics clinics.

\section{Abbreviations}

Edinburgh postnatal depression scale, EPDS

receiver operating characteristic, $\mathrm{ROC}$

area under the curve, AUC

\section{Declarations}

Ethics approval and consent to participate: This research was approved by the Ethics Review Board of the University of Yamanashi (approval number 1663, approval date July 10, 2017) All methods were carried out in

Page 16/20 
accordance with the principles of the Helsinki Declaration. Written informed consent was obtained from all study subjects.

Consent for publication: Not applicable

Availability of data and materials: The datasets generated and/or analyzed during the current study are not publicly available due to protect personal information but are available from the corresponding author on reasonable request.

Competing interests: Not applicable

Funding: This study was supported by Health and Labour Sciences Research Grants (19DA1003). The fundder of this research did not interfere with the design, data collection, analysis, or writing for this project.

Authors' contributions:

HK planned the research, collected patient data, and was a major contributor in writing the manuscript.

RS, YA, and MK analyzed and interpreted the patient data.

YM provided assistance in planning the research and writing the paper.

MY and TY collected patient data.

ZY provided assistance in planning the research and interpreted the patient data.

All authors read and approved the final manuscript

Acknowledgments:

We would like to express our gratitude to the outpatient staff of the Osaka Women's and Children's Hospital, Seibo Hospital, and Showa University Hospital for their cooperation in this study.

\section{References}

1. Ministry of Health. LaW. Results Investig Child Abuse Deaths Numer Child Abuse Consult. 2020.

2. Sakai S, Nagamitsu S, Koga H, Kanda H, Okamatsu Y, Yamagata Z, et al. Characteristics of socially high-risk pregnant women and children's outcomes. Pediatr Int. 2020;62(2):140-5.

3. Kawaguchi H, Fujiwara T, Okamoto Y, Isumi A, Doi S, Kanagawa T, et al. Perinatal determinants of child maltreatment in Japan. Front Pediatr. 2020;8:143.

4. Sidebotham P, Heron J, ALSPAC Study Team. Child maltreatment in the "children of the nineties": a cohort study of risk factors. Child Abuse Negl. 2006;30(5):497-522.

5. Runa I, Yasuhiro Y, Yumi H, Eiko T, Masazumi Y, Motomu A, et al. Selection criteria and progress of mothers require cares in our hospital. J Jp Soc Psychosom Obstet Gynecol. 2020; 24(3): 237-41.

6. Yoshifumi K, Masumi T, Takeshi S, Seon-Hye KIM, Takayuki H, Kazunori U. The background of specified expectant mothers in our institution. Journal of Japan Society of Perinatal and Neonatal Medicine. 2018;54:965-8.

Page $17 / 20$ 
7. Kitamura T, Yoshida K, Okano T, Kinoshita K, Hayashi M, Toyoda N, et al. Multicentre prospective study of perinatal depression in Japan: incidence and correlates of antenatal and postnatal depression. Arch Womens Ment Health. 2006;9(3):121-30.

8. Ministry of Health. LaW. Healthy Parents Child. 2013;21.

9. Poyatos-León R, García-Hermoso A, Sanabria-Martínez G, Álvarez-Bueno C, Cavero-Redondo I, MartínezVizcaíno V. Effects of exercise-based interventions on postpartum depression: A meta-analysis of randomized controlled trials. Birth (Berkeley Calif). 2017;44(3):200-8.

10. Sockol LE, Epperson CN, Barber JP. Preventing postpartum depression: a meta-analytic review. Clin Psychol Rev. 2013;33(8):1205-17.

11. Missler M, Donker T, Beijers R, Ciharova M, Moyse C, de Vries R, et al. Universal prevention of distress aimed at pregnant women: a systematic review and meta-analysis of psychological interventions. BMC Preg Childbirth. 2021;21(1):276.

12. Tachibana Y, Koizumi N, Mikami M, Shikada K, Yamashita S, Shimizu M, et al. An integrated community mental healthcare program to reduce suicidal ideation and improve maternal mental health during the postnatal period: the findings from the Nagano trial. BMC Psychiatry. 2020;20(1):389.

13. Baba S, Kimura T, Ikehara S, Honjo K, Eshak ES, Sato T, et al. Impact of intention and feeling toward being pregnant on postpartum depression: the Japan Environment and Children's Study (JECS). Arch Womens Ment Health. 2020;23(1):131-7.

\section{Figures}

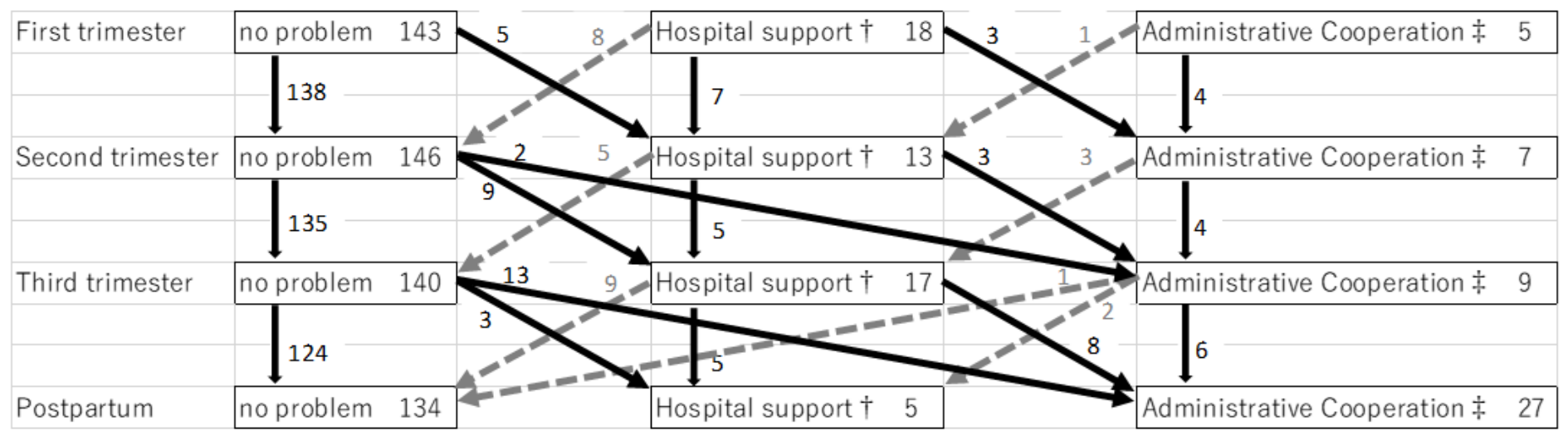

\section{Figure 1}

The change in support status during pregnancy and postpartum

There was a change in the support status during pregnancy.

†Hospital support: socially high-risk pregnant women who were supported by their respective obstetric institutions ¥Administrative cooperation: pregnant women in need of support to require collaboration with public health center 


\begin{tabular}{|c|c|}
\hline & STEP-1 \\
\hline 22 points or more & $\begin{array}{l}\text { Maternal feelings toward being pregnant: confused, trouble, did not feel } \\
\text { anything to be pregnant【 } 7 \text { points】 } \\
\text { Depression symptoms : sometimes/often【 } 2 \text { points】 } \\
\text { Family and social support : no【12 points】 } \\
\text { Economic status: deprived /need of public assistance【8 points】 } \\
\text { Partner's status: unmarried/ remarried【 } 13 \text { points】 } \\
\text { Maternal mental disorder: yes【 } 16 \text { points】 } \\
\text { Worries about older child: yes【 } 3 \text { points】 } \\
\text { Number of fetuses: multiple pregnancies【 } 11 \text { points】 } \\
\text { Number of children: } \geqq 3 【 14 \text { points】 } \\
\text { Maternal age : }<25 【 21 \text { points】 }\end{array}$ \\
\hline & $\underbrace{n}_{\text {STEP-2 }}$ and \\
\hline at least one & $\begin{array}{l}\text { Family and social support: No } \\
\text { Maternal mental disorder: Yes } \\
\text { Worries about older child: Yes } \\
\text { Number of fetuses: multiple pregnancies }\end{array}$ \\
\hline \multicolumn{2}{|r|}{ STEP-3 } \\
\hline at least two & $\begin{array}{l}\text { Depression symptoms: sometimes/often } \\
\text { Maternal mental disorder: yes } \\
\text { Consultation request: yes }\end{array}$ \\
\hline
\end{tabular}

\section{Figure 2}

The screening tool at first visit

Pregnant women with score of 22 points or more were selected as STEP-1. Then, pregnant women are narrowed down as STEP 2 and 3 according to the items on the interview sheet at first visit. 


\begin{tabular}{|l|l|}
\hline \multicolumn{2}{|c|}{ STEP-1 } \\
\hline & Maternity life: difficulty /anxiety【17 points】 \\
& Talking with partner: very few /nothing【11 points】 \\
& Partner violence: yes【15 points】 \\
& Parent's own childhood abuse: yes【14 points】 \\
Depression symptoms : sometimes/often【6 points】 & Family and social support : no【7 points】 \\
& Smoking: continued after pregnant【17 points】 \\
& Consultation request: yes【5 points】 \\
\hline
\end{tabular}

\begin{tabular}{|l|l|}
\hline \multicolumn{1}{|c|}{ STEP-2 } \\
\hline at least one & $\begin{array}{l}\text { Talking with partner: very few /nothing } \\
\text { partner violence: yes } \\
\text { smoking: continued after pregnant }\end{array}$ \\
\hline
\end{tabular}

\section{Figure 3}

The screening tool during second trimester

Pregnant women with score of 14 points or more were selected as STEP-1. Then, pregnant women are narrowed down as STEP 2 and 3 according to the items on the interview sheet during the second trimester. 